\title{
PSICOPATOLOGIA DO TRABALHO ${ }^{1}$
}

\author{
Paulo César Zambroni-de-Souza \\ Anísio José da Silva Araújo
}

Em 2012, foi publicado, na França, o livro Psychopathologie du travail (Dejours \& Gernet, 2012), que certamente atrai quem se interessa pelo campo da Psicologia do Trabalho e Organizacional. Trata-se do mais novo livro de Christophe Dejours, psiquiatra e psicanalista, professor do Conservatório Nacional de Artes e Ofícios (CNAM) de Paris, que publica no Brasil desde 1987 (Dejours, 1987). Sua mais recente obra traduzida para o português abordou o tema do suicídio no trabalho (Dejours \& Bègue, 2010). Ele escreveu o livro objeto desta resenha em coautoria com Isabelle Gernet, professora da Universidade de Paris-Descartes, no Laboratório de Psicologia Clínica e Psicopatologia, e membro da equipe de pesquisa "Psicodinâmica do trabalho e da ação" no mesmo CNAM de Dejours.

O livro que ora resenhamos pertence à coleção "Les âges de la vie" (As idades da vida) dedicada à psicopatologia, publicada na França pela Editora Elsevier Masson. A obra aqui em foco "propõe uma apresentação dos fundamentos teóricos permitindo dar conta da inteligibilidade e da significação das condutas humanas em situação de trabalho" (Dejours \& Gernet, 2012, p.V). Talvez em função das exigências colocadas pela coleção, o próprio título do livro pode deixar confuso o leitor contumaz dos textos de Dejours, já que desde a década de 1990 ele argumenta ser preferível outra expressão (Psicodinâmica do Trabalho - PDT), como escrevera: “a 'psicopatologia do trabalho' é demasiadamente estreita para responder às novas questões, e somos obrigados a vislumbrar uma perspectiva mais ampla: a da psicodinâmica do trabalho" (Dejours, 2004, p. 48). Aqui, seguindo a lógica da coleção, eles falam em Psicopatologia do trabalho (PPT), argumentando que ela passou por uma "renovação" (Dejours \& Gernet, 2012, p. 14).

O livro faz um chamado à Psicanálise como referência teórica central para compreensão psicopatológica. Dejours recorre a ela desde o início de sua trajetória e, neste livro, ela ganha um lugar fundamental, mais explicitamente que em geral encontramos em outros textos seus. Articula a tese da centralidade da sexualidade e do trabalho na construção da identidade com a ideia de que os problemas psicopatológicos no trabalho contemporâneo estão relacionados às condições sociais e organizacionais nas quais ele é realizado.

O livro está dividido em três partes.

$\mathrm{Na}$ primeira delas, "Psicopatologia e psicodinâmica do trabalho: abordagem conceitual", os autores resgatam brevemente a história da PPT e repassam conceitos e noções centrais da PDT, como: sofrimento, "um vivido específico resultante da confrontação dinâmica dos sujeitos com a organização do trabalho" (p. 14); prazer, que "pode estar ao encontro do trabalho quando o sofrimento pode se transmutar em exigência de trabalho pelo Ego e se transformar em experiência estruturante para a identidade" (p. 18); normalidade, resultado "de um compromisso entre o sofrimento e as defesas elaboradas para suportar este sofrimento" (p. 20); estratégias de defesas individuais e coletivas, que são "toda uma série de processos psíquicos que vão contribuir para lutar contra a ameaça de descompensação" (p. 21); inteligência no trabalho, que "se pode dar o nome de 'engenhosidade', em vista de evidenciar seu caráter inventivo e prático baseado na experiência de trabalho" (p. 35); coordenação, que "designa a prescrição dada pela organização do trabalho de relação entre os indivíduos" (p. 44); cooperação, que "designa os laços entre os sujeitos em via de realizar voluntariamente uma obra comum" (p. 44); divisão sexual do trabalho, organizada pelo "princípio da separação (entre trabalhos de homens e trabalhos de mulheres) e o princípio da hierarquia: um trabalho de homem tem mais 'valor'

1 Dejours C., \& Gernet I. (2012). Psychopathologie du travail. Issy-les-Moulineaux: Editeur Elsevier Mason.

* Doutor em Psicologia Social pela Universidade do Estado do Rio de Janeiro (2006), tendo realizado Estágio de Doutorado no Département d'Ergologie - Analyse Pluridisciplinaire de Situations de Travail da Université de Provence, França (2005). Professor do Departamento de Psicologia da Universidade Federal da Paraíba.

\# Doutor em Ciências pela Fundação Oswaldo Cruz (2001), professor adjunto da Universidade Federal da Paraíba. 
que um trabalho de mulher" (p. 30). Esse percurso é interessante para os leitores que já conhecem grande parte da obra de Dejours, por encontrar uma apresentação de temas centrais de outra maneira. É também útil para o iniciante, que encontra, em um texto sintético, o arcabouço teórico da PDT.

A segunda parte, "Entidades psicopatológicas ligadas ao trabalho", apresenta dois capítulos: um com os "Princípios da análise etiológica das patologias mentais em ligação com o trabalho", tema que é tão importante em Psicologia do Trabalho e Organizacional em sua relação com o campo da Saúde do Trabalhador. Sua importância se apresenta seja para subsidiar iniciativas de prevenção, seja para atribuir benefícios previdenciários ou indenizações trabalhistas a quem se afasta do trabalho em função de problemas de saúde gerados ou agravados pelo trabalho. Os autores defendem que, em geral, a psiquiatria não leva em conta suficientemente o poder patogênico do trabalho, limitando sua análise à estrutura psicopatológica do sujeito, levando a equívocos, já que "as relações entre funcionamento psíquico e campo social não se articulam de maneira direta, mas são sempre mediatizadas pelo encontro com o real mobilizado pelo trabalho" (p. 64). O outro capítulo apresenta "Entidades psicopatológicas ligadas ao trabalho" em uma estrutura de texto muito interessante: fazem uma breve descrição do quadro psicopatológico, seguido dos itens "clínica", "análise", "ilustração clínica". Infelizmente nem todas as entidades ou seus subtipos vêm acompanhados da ilustração, que contribuiria para melhor compreendêlos. Neste capítulo, as entidades apresentadas são: Transtornos do humor; Psicoses ligadas ao trabalho; Patologias pós-traumáticas (Síndrome subjetiva póstraumática; Sinistrose; Neurose traumática) e violência no trabalho; Patologias do assédio (sexual; moral); Patologias de sobrecarga (Karoshi; Transtornos musculoesqueléticos; Síndrome do esgotamento profissional ou burn out); Hiperatividade e dopagem no trabalho; Transtornos do julgamento e do pensamento; Suicídios e tentativas de suicídio; Psicopatologia do desemprego.

Os autores argumentam que seria conveniente haver uma lista de patologias profissionais especificamente psicopatológicas. No Brasil já temos essa lista incluída dentre as doenças oficialmente reconhecidas pelo Ministério da Saúde (2001), o que favorece o estabelecimento do nexo causal entre trabalho e transtornos mentais, permitindo ganhos jurídicos e previdenciários para os trabalhadores. Por outro lado, tal lista acaba trazendo limitações, já que o adoecimento dos trabalhadores não se restringe ao que se apresenta naquele quadro e, como a própria PDT defende, há inúmeras formas de sofrimento no trabalho que não chegam a se configurar em patologia à custa de enormes esforços individuais e coletivos dos trabalhadores.

A terceira parte, "Intervenções e perspectivas terapêuticas", inicia-se tratando dos "Elementos da legislação do trabalho" na França, focando dois aspectos: assédio; riscos psicossociais. A seguir, traz uma brevíssima apresentação do tema "Reinserção e readaptação pelo trabalho", defendendo que se devem oferecer condições para que o sujeito possa se apropriar dos investimentos que faz naquele meio de trabalho, valendo-se de uma atividade adaptada às suas dificuldades. Em outro, apresenta os "Dispositivos institucionais" franceses para lidar com as questões de saúde e trabalho. Traz também uma apresentação sobre "Os atores engajados nas questões de psicopatologia do trabalho" e uma breve exposição crítica dos "Métodos de intervenção na empresa". Infelizmente esses capítulos são muito curtos. Seríamos beneficiados por uma discussão mais aprofundada sobre todos esses temas que nos são caros e que interessam à Psicologia quando se trata da inserção grupos sociais frágeis. Esperamos que os autores voltem a eles em outra publicação.

Essa parte do livro traz também algo muito interessante, que pode nos iluminar na formulação de terapêuticas em saúde mental do trabalhador. Trata-se do que eles denominam de "Abordagem psicoterápica dos pacientes que sofrem de transtornos psíquicos em relação com o trabalho". Nela, propõem formas de conduzir a terapia com trabalhadores de modo a tocar nos temas: organização do trabalho; cooperação; avaliação; sofrimento ético; gênero; esfera privada; esfera profissional; reconhecimento de injustiças. A apresentação da referida abordagem é breve, despertando também aqui a vontade de que os autores voltem ao tema ulteriormente.

O convite à leitura está feito, desejando que o livro seja também publicado no Brasil.

\section{REFERÊNCIAS}

Dejours, C. (1987). A loucura do trabalho: estudo de psicopatologia do trabalho. São Paulo: Cortez; Oboré.

Dejours C. (2004). Addendum: da psicopatologia à psicodinâmica do trabalho. In: Lancman S., \& Sznelwar, L.I. (Orgs.), Christophe Dejours: da psicopatologia à psicodinâmica do trabalho (pp. 47104). Rio de Janeiro: Editora Fiocruz, Brasília, DF: Paralelo 15. 
Dejours C, Bègue F. (2010). Suicídio e trabalho: o que fazer? Brasília, DF: Paralelo 15.

Ministério da Saúde. (2001). Doenças relacionadas ao trabalho: manual de procedimentos para os serviços de saúde. Brasília, DF: Ministério da Saúde.

\section{Endereço para correspondência:}

Paulo César Zambroni de Souza. Departamento de Psicologia, Universidade Federal da Paraíba, Cidade universitária, s /n ${ }^{\circ}$, Bairro Castelo Branco, CEP 58051-900, João Pessoa-PB, Brasil. E-mail:paulozamsouza@yahoo.com.br 